\section{The facilitation of conditioned alpha blocking with an overt response}

\author{
R. THOMPSON PUTNEY, THOMAS J. ERWIN, and S. TOM SMITH, JR. \\ Georgia State University, Atlanta, Ga. 30303
}

The experiment examined the effects of three instructed response conditions upon the conditioned blocking of the occipital alpha rhythm: (1) response at light UCS onset, (2) response at light offset, and (3) no response. The results indicated that significant conditioning occurred under all three response conditions when compared to tone blocking habituation during unpaired pseudoconditioning. The major conclusions were that response to light onset facilitates conditioned reduction both early and late in conditioning and that making an overt response is not a necessary condition for demonstrating conditioned alpha reduction.

The past decade of research on the conditioned blocking of the human occipital alpha rhythm contains serious inconsistencies with the previous literature, including a substantial questioning about whether or not such conditioning occurs (Esecover et al, 1964; Milstein, 1965; Stern et al, 1961). One of the major procedural variations among reported experiments, which may account for the contradictory findings, is the way in which the $S$ is instructed in the conditioning situation. Experiments in which the $S$ is instructed to make some overt response (Jasper \& Shagass, 1941; Putney, 1966), such as a keypress at the onset of the light unconditioned stimulus (UCS) or a self-paced instructed fist clench as the conditioned stimulus (CS) (Shagass, 1942; Shagass \& Johnson, 1943), contain clear evidence of conditioning. Other research in the field has either involved instructions to Ss to remain relaxed and passive with eyes either open or closed or there is no mention of the nature of instructions. These studies range from ones clearly demonstrating conditioning (Torres, 1968a) to those in which no evidence of conditioning is obtained (Stern et al, 1961), or in which apparent conditioning can just as well be accounted for as pseudoconditioning (Esecover et al, 1964; Milstein, 1965). In addition, there is a substantial middle ground in which conditioned alpha reduction is described as a weak or unstable phenomenon (Albino \& Burnand, 1964; Gastaut et al, 1957; Knott \& Henry, 1941; Travis \& Egan, 1938). The strongest conclusion one might draw from this literature is that making an overt response is necessary for conditioning. Only Torres's (1968) study presents evidence of conditioning without an overt response, which is different from the level of blocking in the pseudoconditioning control group seldom used in other studies.
The present study was undertaken to examine how conditioned alpha reduction is affected by instructing $S$ to make a response. To this end, three conditions were used: response at light onset, response at light of fset, and no overt response. The light offset condition was used as a control to determine whether facilitation of conditioned reduction before light onset was due to a maintenance of alertness by instructing $S$ to be active during a session or was more specifically related to the readiness to respond during the interstimulus interval in the response at light onset condition. A within-S pseudoconditioning control procedure and a continuous method of quantifying the CR previously used by Putney (1966) were also used here. Together, they provide a rigorous test not found in other conditioning studies of whether or not conditioning occurred under all response treatments, as well as to demonstrate any differences among them.

$$
\text { METHOD }
$$

The Ss were 12 undergraduates (2 men, 10 women) from introductory psychology courses at Georgia State University. All Ss had moderate to persistent alpha.

The EEG was recorded on a Grass Model 78 polygraph from the scalp, using polished silver electrodes placed over left or right occipital regions, with the left earlobe as reference. The raw EEG was filtered through a Kronhite filter set with the $3-\mathrm{dB}$ points to pass $7.5-12.5 \mathrm{~Hz}$ and was recorded on paper along with the raw record and stimulus channels.

The $\mathbf{S}$ sat in a reclining chair facing a translucent window in an Industrial Acoustics Company room. The UCS was a $150-W$ flood lamp outside the room presented through the window approximately $6 \mathrm{ft}$ from $\mathrm{S}$. The CS was a $400-\mathrm{Hz}$ tone of moderate intensity presented through a speaker $5 \mathrm{ft}$ in front of S. During conditioning the 3-sec tone was presented $1 \mathrm{sec}$ before and overlapped $2 \mathrm{sec}$ with the 3 -sec light. Goggles with Mylar lenses were worn to prevent pattern vision, and $S$ was instructed to keep eyes open.

Stimulus presentations were given when S's alpha reached a preset amplitude criterion. Trials were triggered by the first seven alpha waves during $.80 \mathrm{sec}$ after randomly ordered minimum intertrial intervals (ITI) of 5 , 10 , and $15 \mathrm{sec}$. The criterion amplitude for the series of alpha waves was arbitrarily set using a Schmitt trigger in order to give trials consistently as soon after the minimum ITI as possible.

Each session began with the pseudoconditioning control consisting of 20 tones and 20 lights presented randomly and was followed by 30 conditioning trials and extinction consisting of 10 tones and 10 lights not reported here. The randomly presented tone-light sequence provided a baseline of habituated responding to tone under the pseudoconditioning procedure against which the level of conditioning could be assessed. The sessions differed only in instructions: (1) leverpress to light onset, (2) light offset, or (3) to make no response at all. All lights during response conditions were responded to both when paired and not paired with tones. The three instruction conditions were completely counterbalanced across the three sessions, with two Ss in each of the six possible orders of the three conditions.

The data were reduced by placing a millimeter-ruled template over the filtered record, positioned in constant relation to the stimulus marker channel and zero value of the filtered record. The individual amplitudes were measured for the three waves just preceding the tones and the first three waves 1 sec after the onset of tone stimulation during pseudoconditioning or immediately following light during the tone-light conditioning trials. The latter waves were previously shown by Putney (1966) to demonstrate the greatest conditioned reduction, and they also just precede the beginning of unconditioned blocking to light during the preliminary pseudoconditioning light presentations. The dependent variable consisted of the proportion of reduction of the three waves following the first second of tone from the three prestimulus waves.

\section{RESULTS}

The pseudoconditioning and conditioning results appear in proportion reduction form in blocks of two trials in Fig. 1. Except for the first block, all others represent running averages with the block in front and behind the reference one. The 


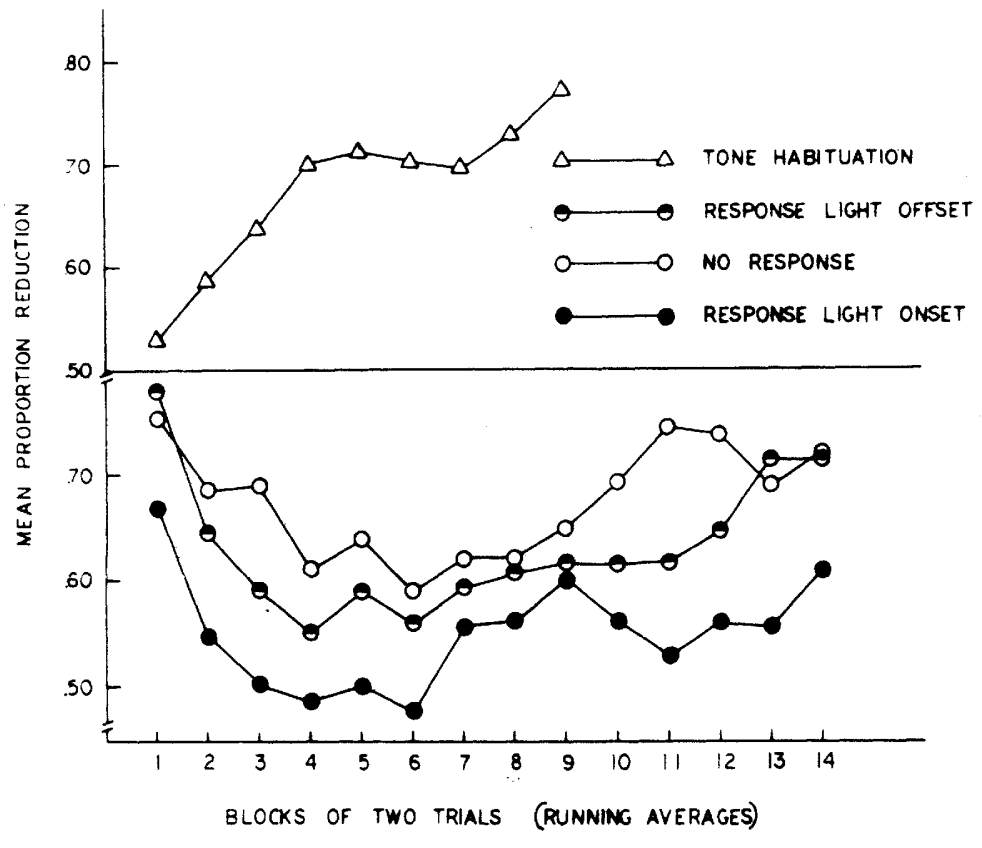

Fig. 1. Habituation (upper panel) and conditioning (lower panel) under the three response conditions, in blocks of two trials using running averages except for Trial Block 1.

unpaired presentations of tone and light resulted in a substantial habituation to the tone, which was virtually the same for all three sessions. Therefore, they were pooled in Fig. 1. The conditioning trends in contrast were all nonmonotonic with an early portion descending to Block 6, followed by a mainly ascending arm reflecting loss of CR strength. The smallest loss of $\mathrm{CR}$ was in the response onset condition. Page's $\mathrm{L}$ test of monotonic trend (Page, 1963) was used in order to contrast statistically the early descending portion of the conditioning curves with tone habituation. Raw rather than running averages were used for these and all other $\mathrm{L}$ tests. The proportion reduction for each of the first five blocks of two trials of conditioning was subtracted from the corresponding blocks for unpaired tones for each $S$, yielding difference scores. The differences were then ranked according to the L-test procedure, separately for each instruction condition. The resulting monotonic separation in trends for the first 10 trials of habituation and conditioning yielded significant values of $\mathrm{L}$ for response at light onset $(\mathrm{L}=604, \mathrm{p}<.001)$, response at light offset $(L=593, p=.001)$, and no response $(\mathrm{L}=586, \mathrm{p}<.01)$. In addition, tone habituation had a significant upward trend of decreasing proportion reduction for both the first $5(\mathrm{~L}=592, \mathrm{p}<.01)$ and all 10 blocks of two trials $(\mathrm{L}=3940, \mathrm{p}<.001)$. All three response conditions had significant downward trends ( $L=580$, $\mathrm{L}=574$, and $\mathrm{L}=576, \quad \mathrm{p}<.05$, respectively, for onset, offset, and no response).

The major differences in the three instruction conditions were assessed by grouping the 30 trials in means of 10 trial blocks (see Table 1 ). Since the light offset condition was used as a control for noncontingent alertness, it was pooled with the passive condition in order to obtain contrasts with the light onset condition, using two-tailed Wilcoxon tests (T). The resulting tests indicated that light-onset responding produced a significantly greater proportion reduction than did the other two conditions together during the first $(T=14, p=.05)$ and third segments of conditioning ( $T=7$, $\mathrm{p}=.01$ ), but not during the middle $(\mathrm{T}=29, \quad \mathrm{p}>.20)$. The simple comparisons for the light onset and no-response conditions were also significant for the first $(T=10$ $\mathrm{p}=.02)$ and last $(\mathrm{T}=4, \mathrm{p}<.01)$ trial blocks. Finally, the overall level of alpha reduction was significantly lower for light onset than for light offset $(\mathrm{T}=14, \mathrm{p}=.05)$ and no response $(\mathrm{T}=2, \quad \mathrm{p}<.01)$. No other comparisons were significant.

\section{DISCUSSION}

The results show that conditioning was demonstrated under all response conditions, since they all had trends significantly different from the trend. Therefore, the conclusion unpaired pseudoconditioning tone follows that making a voluntary response close in time to UCS onset facilitates the level of conditioning but is not a necessary condition for it. Further, it appears that the facilitation is not due only to the maintenance of alertness to prevent an active response, since the response-offset and no-response groups had marked nonmonotonic trends which were, together, higher than response onset both in the first and last block of 10 trials; the two groups also individually had significantly higher total reduction.

Since conditioning was demonstrable when Ss were instructed not to respond, previously reported weak and unstable conditioning under such conditions must be interpreted as the result of the methods used, particularly less sensitive procedures for quantifying alpha reduction. The most frequently used procedure, first used by Knott \& Henry (1941), has been to score an alpha block as occurring if three or more waves in a given epoch (e.g., $1 \mathrm{sec}$ ) are $50 \%$ below prestimulus waves. As previously mentioned, only Torres (1968) has successfully used this binary criterion to show conditioning contrasted with an independent pseudoconditioning control group. Further, the contrast between acquisition and habituation functions, he reports, is less clearly marked than the ones reported both here and previously by Putney (1966) using proportion reduction. The present data also further confirm the finding by Putney (1966) that the binary criterion is too conservative to demonstrate conditioning easily. This is particularly true in the response at offset and no-response conditions where relatively few individual proportions fall below $50 \%$, yet conditioning was demonstrated to be different from pseudoconditioning. Therefore, the efficacy of using a continuous measure, first suggested by Knott \& Henry (1941), instead of a binary criterion of alpha reduction is amply supported, since it in part helps to explain some previous inconsistencies in finding clear vs unclear evidence of conditioning, particularly where uninstructed Ss have been used.

Table 1

Mean Proportion Reduction in Alpha Amplitude for Blocks of 10 Trials and Three Response Treatments During Conditioning

\begin{tabular}{lcccc}
\hline & \multicolumn{5}{c}{ Trial } & Block \\
\cline { 2 - 5 } Response & $1-$ & $11-$ & $21-$ \\
Light & 10 & 20 & 30 & Total \\
\hline Onset & .524 & .556 & .574 & .551 \\
Offset & .618 & .602 & .690 & .636 \\
No Response & .676 & .636 & .737 & .683 \\
\hline
\end{tabular}


One could argue that the conditioning results obtained here are not particularly strong on the basis of the amount of loss of the CR strength in the latter part of the three acquisition functions, although the ascending arm of the response onset condition is less than those for the other conditions. However, this is not an unfamiliar effect in the conditioning literature and was early labeled inhibition of reinforcement by Hovland (see Kimble, 1961, p. 125f). Studies of GSR conditioning commonly contain nonmonotonic acquisition curves showing the same $\mathrm{CR}$ loss found here (e.g., Morrow \& Keough, 1968), particularly under nonoptimal values of conditioning parameters. Therefore, it remains to be seen if a smaller CR loss can be shown for conditioned alpha reduction with longer ITIs and with a more intense UCS.

\section{REFERENCES}

ALBINO, A. R., \& BURNAND, G. Conditioning of the alpha rhy thm in man.
Joumal of Experimental Psychology, $1964,67,539-544$.

ESECOVER, H. B., TORRES, A. A. TAYLOR, R. M,, WILKENS、B., \& MALITZ, S. Contingent alpha blockin and sensitization. Nature, 1964,201 1247-1248.

GASTAUT, H., JUS, A., JUS, C. MORRELL, F., STORM Van LEEUWEN W. DONGIER, S., NAQUET, R., REGIS H., ROGER, A., BEKKERING, D. KAMP, A., \& WERRE, J. Étude topographique des réactions électroencéphalographiques conditionées chez l'homme. Electroencephalography \& Clinical Neurophysiology, 1957, 9, 1-34

JASPER, H. \& SHAGASS, C. Conditioning in the occipital alpha rhythm in man. Joumal of Experimental Psychology, $1941,28,373-387$.

KIMBLE, G. A. Hilgard and Marquis' Conditioning and learning. (rev. ed.) New York: Appleton-Century, 1961

KNOTT, J R \& HENRY, C, E, The conditioning of the blocking of the alpha $r$ h $\mathrm{th} \mathrm{m}$ of $\mathrm{the} h \mathrm{hm} \mathrm{n}$ electroencephalogram. Journal of Experimental Psychology, 1941, 28 , 134-144.

MILSTEIN, V. Contingent alpha blocking: Conditioning or sensitization. Electroencephalography \& Clinical Neurophysiology, $1965,18,272-277$.

MORROW, M. C.. \& KEOUGH, T. E. GSR conditioning with long interstimulus intervals. Journal of Experimental Psychology, 1968, 77, 460-467.

PAGE, E. G. Ordered hypotheses for multiple treatments: A significance test for linear ranks. Journal of the American Statistical Association, 1963, 58, 216-230.

PUTNEY, R. T. A quantitative evaluation of conditioned blocking, enthancement, and inhibition of reinforcement of the alpha rhy thm. Unpublished doctoral dissertation. University of Missouri, 1966.

SHAGASS, C. Conditioning the human occipital rhythm to a voluntary stimulus. A quantitative study. Journal of Experimental Psychology, 1942, 31, 201-209.

SHAGASS, C., \& JOHNSON, E. P. The course of acquisition of a conditioned response of the occipital alpha rhythm. Journal of Experimental Psychology, $1943,33,367-379$.

STERN, J. A., DAS, K. C., ANDERSON, J. M., BIDDY, R. L., \& SURPHLIS, W. "Conditioned" alpha desynchronization. Science, 1961, 134, 388-389.

TORRES, A. A. Sensitization and association in alpha blocking "conditioning." Electroencephalography \& Clinical Neurophysiology, 1968, 24, 297-306.

TRAVIS, L. E., \& EGAN, J. P. Conditioning of the electrical response of the cortex. Journal of Experimental Psychology $1938,22,524.531$.

\section{Brain Functions}

ALTMAN, J. L., \& WISHART, T. B. Motivated feeding behavior elicited by electrical stimulation of the septum. Physiology \& Behavior, 1971, 6, 105-109.

BALAGURA, S., \& DAVENPORT, L. D. Lateral hy pothalamus: Reevaluation of function in motivated feeding behavior. Science, 1971, 172, 744-746.

BLASS, E. M., \& EPSTEIN, A. N. A lateral preoptic osmosensitive zone for thirst in the rat. Journal of Comparative \& Physiological Psychology, 1971, 76, 378-394.

KISSILEFF, H. R. Acquisition of prandial drinking in weanling rats and in rats recovering from lateral hypothalamic lesions. Journal of Comparative \& Physiological Psychology, 1971, 77, 97-109.

KONDO, C. Y., \& LORENS, S. A. Sex differences in the effects of septal lesions. Physiology \& Behavior, $1971,6,481-485$.

LEPKOVSKY, S. FURUTA, F., SHARON, I. M., \& SNAPIR, N. Thirst and behavior in adipsic chickens with hypothalamic lesions before and after intravenous injection of hypertonic $\mathrm{NaCl}$ solution. Physiology \& Behavior, $1971,6,477-480$.
LORENS, S. A., \& KONDO, C. Y. Differences in the consummatory and operant behaviors of male and female septal rats. Physiology \& Behavior, 1971, 6, 487-491.

MOGENSON, G, J. Stability and modification of consummatory behaviors elicited by electrical stimulation of the hypothalamus. Physiology \& Behavior, 1971, 6, 255-260.

MYERS, R. D., \& VEALE, W. L. Spontaneous feeding in the satiated cat evoked by sodium or calcium ions perfused within the hypothalamus. Physiology \& Behavior, 1971, 6, 507-512.

SCHACHTER, S. Some extraordinary facts about obese humans and rats. American Psychologist, 1971, 26, 129-144.

SMITH, C. J. V., \& BRITT, D. L. Obesity in the rat induced by hypothalamic implants of gold thioglucose. Physiology \& Behavior, $1971,7,7-10$.

SMITH, D. F., BALAGURA, S., \& LUBRAN, M. Antidotal thirst and lithium excretion in rats with hypothalamic lesions. Physiology \& Behavior, 1971, 6, 209-213.

SORENSEN, J. P., JR., \& HARVEY, J. A. Decreased brain acetylcholine after septal lesions in rats:
Correlation with thirst. Physiology \& Behavior, 1971, 6, 723-725.

WISE, C. D., STEIN, L., \& BERGER, B. D. Norepinephrine: Reversal of anorexia in rats with lateral hypothalamic damage. Science, $1971,172,281-284$.

WISE, $R$. A. Individual differences in effects of hypothalamic stimulation: The role of stimulation locus. Physiology \& Behavior, 1971, $6,569-572$.

\section{Polydipsia}

COLOTLA, V. A., \& BEATON, J. M. Concurrent palatability-induced and schedule-induced polydipsia in rats. Psychological Record, 1971, 21, 145-150.

FREED, E. X. Effects of conflict upon schedule-induced consumption of water and alcohol. Psychological Reports, 1971, 29, 115-118.

KEEHN, J. D. Stimulus and subject control of schedule-induced drinking. Journal of the Experimental Analysis of Behavior $1971,16,257-262$

PALFAI, T., KUTSCHER, C. L., \& SYMONS, J. P. Schedule-induced polydipsia in the mouse. Physiology \& Behavior, 1971, 6, 461-462.

(Continued on page 52) 